\title{
Improvements of Techniques to Estimate Migration Rates: An Application with Brazilian Censuses Data
}

\author{
Ernesto F. L. Amaral \\ João Pinheiro Foundation (FJP), Brazil \\ eflamaral@gmail.com
}

\begin{abstract}
This paper intends to develop procedures which can be applied to different countries and databases to estimate migration rates using information on place of previous residence (last-move data) and duration of residence. For this, some modifications are proposed to previous methods, in order to improve the measurement of migration rates. Other estimations were calculated with information on place of residence at some fixed date in the past. Results suggest that estimations with improved techniques using last-move data give similar results to those ones provided by techniques based on place of residence from a specified number of years preceding the Census enumeration. As a demonstration, 1970, 1980, 1991 and 2000 Brazilian Censuses are used to estimate both sets of rates.
\end{abstract}

\section{Keywords}

Migration. Place of previous residence. Last-move data. Place of residence at a fixed date in the past. Duration of residence. Age-specific emigration rates (ASER). Total emigration rates (TER).

\section{Acknowledgments}

I am grateful to José Alberto Carvalho, Moema Fígoli, Joseph Potter, José Irineu Rigotti, Bryan Roberts, Carl Schmertmann, the reviewers of Population Review, and mostly to Roberto Rodrigues for his valuable suggestions and comments. I would also like to thank Adriane Reams for editing this manuscript.

\section{Final publication}

Amaral EFL. 2008. "Improvements of techniques to estimate migration rates: An application with Brazilian Censuses data." Population Review, 47(2): 1-24.

(http://dx.doi.org/10.1353/prv.0.0007) 


\section{Introduction}

The focus of this paper is to attempt to estimate a series of migration rates for inter-Census periods, while the questions have been changing on Censuses data through the years. That poses some interesting methodological problems that can be related to migration studies developed in other countries.

Bell (2005) develops a study comparing countries around the world in relation to the migration questions collected by their national statistical offices. More specifically, Bell intended to collect data for the 191 member countries of the United Nations at the time of his study. ${ }^{1}$ Data was collected for 165 countries, from which 162 collected internal migration information in some form, and 141 collected such information from Censuses. Among the countries that collected migration information on Censuses, 115 of them have information on place of birth (within the country), 126 collected place of residence at some other prior date, and 82 have information on duration of residence. In relation to the information on previous place of residence at some prior time (also defined as transition data, movements that happened since birth), 28 countries collected residence at a fixed interval of five years, 56 utilized a five year interval, 34 countries did not specify an interval (capturing the last transition), and 29 countries had some other length interval.

Usually, information on place of residence at a fixed number of years prior to the Census is highlighted as the one suited to estimate internal migration (UNECE 2005). However, Xu-Doeve (2006) emphasizes that the best approach to measure migration is based on information on duration of residence, and place of previous residence (last-move data). Following his recommendations for the measurement of migration in the next global round of population Censuses, Xu-Doeve indicates that "internal migration is most suitably measured by a question on the unbroken duration of residence in the current place of usual residence, supplemented by a question on the previous place of usual residence" (Xu-Doeve 2006: 10). He points out that the exact date of the move is reported by the duration of residence, which provides the full reconstruction of migration processes as they took place in real time.

Xu-Doeve argues that only migration data on continuous time (last-move data and duration of residence) provides an analysis on different scopes: (1) estimation of consistent instantaneous migration rates, along cohort lines, as a function of continuous time and age; (2) estimation of probabilities to make several moves within specified times intervals (multiple moves and migration trajectories); (3) estimation of migrant stocks (described in absolute numbers); (4) calculation of period rates; (5) adjustment of migration data for incompleteness of enumeration; and (6) computation of transitions in any arbitrarily specified discrete interval of time and age. More specifically, this data enables the estimation of intra-period trends of migration transitions (Schmertmann 1999). 
If only place of residence at some fixed date in the past is available, with no information on last-move data and duration of residence, some limitations to the study of migration are evident: (1) impossibility to estimate cohort instantaneous migration rates as a function of continuous time and age, because the analysis is in discrete time; (2) no proper available data to estimate multiple moves and migration trajectories; (3) estimation of migrant stocks and flows is not properly identified; (4) migration rates obtained are not consistent with the standard definition of occurrence/exposure rates (denominator is not the number of person-years exposed to the risk of migration); (5) no correction for undercount enumeration of migrants can be done; and (6) only allows the estimation of migration transitions in discrete time and age between the fixed date in the past and the date of enumeration.

In the present paper, I will concentrate on the analysis of topic 6 exposed in the previous two paragraphs: estimation of transitions in discrete time and age, comparing estimations of last-move data and duration of residence, to those of place of residence at a fixed prior date. As discussed by Bell (2005), different kinds of data are available in Censuses of different countries worldwide. Consequently, demographers can maximize the use of the available data with techniques that can estimate migration transitions with both sets of variables: (1) last-move data and duration of residence; and (2) place of residence at a fixed date in the past. Thus, my intention is to explain and improve such techniques that can be used for the wide range of countries that collect migration information on their Censuses.

One example of a study that tried to estimate migration rates with last-move data and duration of residence was the one proposed by Machado (1993). This methodology allows for the estimation of indicators related to a whole country, as well as to particular areas or regions within the country. Although Machado's methods provided important improvements to estimate migrant rates, using information on continuous time to estimate rates on specific discrete intervals of time, some problems with the formula arise. These techniques will be explained, their limitations will be exposed, and further improvements will be proposed with the goal of advancing migration estimations that can be applied to different countries and databases.

I intend to verify the technical procedures by using real migration data. The 1970, 1980, 1991 and 2000 Brazilian Censuses microdata (IBGE 1970, 1980, 1991, 2000) were used to check the improvement of the new technique. More specifically, this exercise was applied to migration flows among the five Brazilian major-regions. Machado also calculated those rates by major-regions, using the 1980 Brazilian Census. The new estimates can be compared to rates originated from data on place of residence at a fixed prior date, as well as to those calculated by Machado. 
This article is organized in the following sections. First, explanations of technical procedures used to calculate migration rates, as well as a clarification of equations and terms, are provided. Moreover, corrections in the estimation of migration rates are elucidated in detail. In the next section, a presentation of Brazilian Censuses data is made, as well as an explanation of estimations and migration curves calculated with this data. The subsequent section presents empirical results obtained from Brazilian Censuses. Tables and figures are provided to illustrate migration patterns and levels among selected Brazilian major-regions. Finally, main conclusions and comparisons between the different estimations are exposed in the last section.

\section{Methods}

Before explaining the techniques to estimate migration rates, it is important to make some clarifications about some migration concepts. Rees, Bell, Duke-Williams and Blake (2000) describe a series of migration definitions. They identify "transitions" as the count of migrants making one move between two specific time points. "Transition probabilities" are the ratios of "migrants" to populations at risk of migrating. This population at risk is the starting population of origin related to the migrant count in the numerator. Transition data are derived from population Censuses. Further, "movements" are defined as the counting of each address change occurring at a specific time interval. Thus migrations are defined as counts of events, since migrants can move more than once in a time interval. "Movement rates" are the ratios of "migrations" to populations at risk of migration. In this case, the population at risk is the population exposed to the risk of migration over the time interval. Sometimes this measure cannot be generated directly. Thus some studies use either the linear average of the populations at the beginning and at the end of the interval, or the population in the middle of the period. Movement data are derived from population registers that count changes of address or migrations. Moreover, "flows" are viewed as counts of transitions from regions of origin to regions of destination, as well as counts of movements that took place between regions before the move and those after the move. Thus "migration intensities" are the ratios of migration flows to populations at risk of migration.

In this paper, Censuses data will be used to estimate movement rates. Thus the population at risk of migration has to be calculated in order to properly generate those rates. This information is crucial, and it compounds the denominator of such formulas. Furthermore, these rates take into account that individuals can move more than once in a time period (migrations). At the same time, in the estimations provided below the number of person-years in the denominator indicates that the risk to migrate in each year of the time interval is equivalent to one unit. If someone lived more than one year in a specific region in a time interval, the number of person-years will be proportional to this duration. Thus, there is the assumption that each 
individual migrates just once per year. This assumption is robust when the migration being studied deals with larger regions (as is the case of this paper), making it reasonable to think that no more than one movement happens each year by the same individual.

Brazilian Censuses are used to illustrate how migration rates can be obtained with this data source. Since 1970, these Censuses have a comprehensive set of information suitable for estimation of migration rates, even in comparison to data collected in the developed world. However, only in 1991 data about place of residence five years before the Census began to be collected. In order to generate emigration rates that could be employed for the projection of Brazilian population by its five major-regions (North, Northeast, Southeast, South and Center-West) Machado (1993) developed a technique to estimate migration rates using information on place of previous residence (last-move data) and duration of residence. In fact, he created a new methodology to estimate migration flows, allowing researchers to estimate age-specific migration rates with life history data. This methodology permits the estimation of migration rates using the 1970, 1980, 1991, and 2000 Brazilian Censuses. Varying rates can be generated by utilizing sex and five-year age groups. Moreover, migration rates can be estimated by state, as well as by municipalities, when data is available.

Migration rates can also be generated using information on place of residence five years before the enumeration for the 1991 and 2000 Censuses. Therefore, the estimation developed by Machado can be compared to the other set of estimations from the 1991 and 2000 Censuses. In this paper, rates are calculated using both techniques. The intention is to improve the methodology proposed by Machado, through the addition of terms in the equation, as well as to compare the robustness of these estimations to those originated with information on place of residence at a fixed prior time.

Machado employed the term "specific rates of emigration" to qualify the migration estimative. In this paper, these estimates are named as age-specific emigration rates $\left(A S E R_{x, i j}\right)$. Levels of migration flows will be analyzed on the basis of total emigration rates $\left(T E R_{i j}\right)$. Those terms facilitate the understanding of those estimates, because they can be compared to age-specific fertility rates $\left(A S F R_{x}\right)$ and total fertility rates $(T F R)$, respectively.

It is important to note that the estimation of Machado's migration rates is based on some assumptions. The first being that population is homogenous with regard to migration risk. Another assumes that survival ratios for migrants and non-migrants are the same. Finally, each individual migrates just once per year. 
In the numerator, the equation applied by Machado has the population that migrated from a region $i$ to region $j$ during the five years before a specific Census. The denominator for a region of origin $(i)$ is the number of person-years who were at risk to migrate. The following equation is the one applied by Machado (1993: 90) to estimate age-specific emigration rates using information on place of previous residence (last-move data), and duration of residence:

$$
A S E R_{x, i j}=\frac{\sum_{t=0}^{4} K_{t, i j}^{x}}{K_{1, i}^{x}+2 K_{2, i}^{x}+3 K_{3, i}^{x}+4 K_{4, i}^{x}+5 K_{n m, i}^{x}},
$$

in which $A S E R_{x, i j}$ is the age-specific emigration rate from region $i$ to region $j$ for age group $x$; $K_{t, i j}^{x}$ is the population that migrated from $i$ to $j$ for age group $x$, with duration of residence in the current place of usual residence equal to $t$ ( $t$ equals zero for those that migrated less than one year before the Census); $K_{t, i}^{x}$ refers to migrants who moved from all regions different from $i$ to region $i$ for age group $x$, and live in the place of usual residence for $t$ years; and $K_{n m, i}^{x}$ are all residents in region $i$ at the end of the period that already lived in $i$ at the beginning of the period ( $\mathrm{nm}$ means non-migrants) for age group $x$. The multipliers for each term in the denominator, such as $2 K_{2, i}^{x}$, relate to the number of years of residence in a specific place for age group $x$. This provides the number of person-years exposed to the risk of migration in that period.

For this paper, Machado's equation experienced some changes. Changes on the estimation of the agespecific emigration rate were suggested by Carvalho $^{2}$ and are summarized below. First of all, people who lived less than one year in a specific region need to be included in the denominator.

Another change in the equation concerns the multiplier (weight) for each individual. The weight is not just the number of years of residence in a specific region. The number of years of residence is added by one half to calculate the weight for each individual. This procedure is a common demographic technique when Census data is used, in which the reference date is in the middle of the calendar year. Information on duration of residence has an error measure because the respondent is not taking into account the Census date of reference, but the calendar year. Thus the reason for this correction is that each individual lived, on average, one-half year longer than the amount specified in each Census. Concerned about duration of time gone since the last change of residence, Courgeau, Nedellec, and Empereur-Bissonnet (2000) analyze migration data from France, and estimate survivor functions and hazard rates. They indicate that since the events occurring between durations 0 and 0.5 year are not known, they assume 0.5 year duration as the initial time. In the case of this paper, information on duration of residence can also take the value of zero, if the migrant lived 
in the place of usual residence for less than one year. However, this individual has been living at that location at least since the Census reference date, which is the reason he/she was interviewed. Thus the same procedure is employed, with rates starting their estimation from an initial duration of 0.5 years.

Furthermore, terms that count the number of person-years lived in the region of origin are added in the denominator. These terms have an opposite weight than those weights of the immigrants (region of destination). The sum of weights of emigrants ( $K_{t, i .}^{x}-$ origin) and immigrants ( $K_{t, i}^{x}-$ destination) equals five years, which is the extension of the analyzed period. The $K_{t, i}^{x}$ terms are the ones not employed by Machado, and suggested in this study.

The next equation is utilized in this paper to estimate age-specific emigration rates using previous place of residence (last-move data), and duration of residence:

$$
\operatorname{ASER}_{x, i j}=\frac{\sum_{t=0}^{4} K_{t, i j}^{x}}{0.5 K_{0, i}^{x}+1.5 K_{1, i}^{x}+2.5 K_{2, i}^{x}+3.5 K_{3, i}^{x}+4.5 K_{4, i}^{x}+},
$$

in which $A S E R_{x, i j}, K_{t, i j}^{x}, K_{t, i}^{x}$, and $K_{n m, i}^{x}$ have the same meaning as in Equation (1); and $K_{t, i .}^{x}$ refers to migrants from region $i$ to all regions different than $i$ for age group $x$, with duration of residence in the current place of usual residence equal to $t$. For migrants above five years of age, the sum of weights equals five because they were exposed to the risk of migrating during all period. For all migrants, the two different weights will be applied to distinct regions (origin $-i$, and destination $-j$ ). Thus the origin multipliers in the denominator (place of previous residence $-K_{t, i .}^{x}$ ) are a main contribution to Equation (2), compared to Equation (1), which had only the destination multipliers in the denominator (place of current residence $\left.K_{t, i}^{x}\right)$.

More specifically, a migrant who moved from region $a$ to region $b$, and lives in $b$ for three years will be added to the denominator of the emigration formula from region $b\left(A S E R_{x, b}\right)$ with a weight equal to 3.5 (because he has been living for three years in region $b: 3.5 K_{3, b}^{x}$ ), and he will also be incorporated in the denominator of the emigration formula from region $a\left(A S E R_{x, a}\right)$ with a weight equal to 1.5 (this equals the 
length of the interval minus the weight for the current residence: $1.5 K_{3, a}^{x}$.). Furthermore, this migrant will be added with weight equal to one unit on the numerator of the emigration formula from region $a\left(A S E R_{x, a}\right)$.

Emigrants between zero and five years of age have the origin weights $\left(K_{t, i .}^{0}\right)$ calculated in a specific manner. This weight is the difference between the real child age and the number of years living in the current residence (destination multiplier in the denominator). Because of indirect migration, emigrants between zero and five years of age need to be multiplied by two (in the numerator $-K_{t, i j}^{0}$, and in the origin multipliers part of the denominator $-K_{t, i}^{0}$ ). This correction is due to the fact that in a period of five years, children born in the region of destination of emigrant mothers equal, approximately, the same amount of children born in the region of origin.

To better understand the correction for indirect migration, consider a woman who migrated from $i$ to $j$, and who had one child in $i$ and three children in $j$. The child born in $i$ is going to be counted in the Census as an emigrant from $i$ to $j$. However, the other three children are going to be considered as non-migrants in the Census. The inverse example can also happen: a woman who migrated from $i$ to $j$, and who had three children in $i$ and one child in $j$. The first three children are considered emigrants from $i$ to $j$, and the last child is going to be counted as a non-migrant. There are also cases in which women have children either just in $i$ or just in $j$. In demographic terms, the children who migrated with their parents are considered direct migrants. When the children are born after the migration of their parents they will be considered as the indirect effect of migration. Thus, the multiplier is going to calculate the indirect effect (children born after the migration of their parents) based on the direct effect (children born on the region of origin, and who migrated with their parents). When the children born in the region of origin are multiplied by two, this is an approximated form to correct for an underestimation of migrant infants (since the indirect effect was not taken into account previously). Since these children are multiplied by two in the numerator of the emigration rate from region $i$ to $j$, they also have to be multiplied by two in the denominator of this rate from $i$ to $j$.

When this correction for the indirect effect of migration is estimated, there is the assumption that the emigrant mother (who is considered a recent migrant, since she moved in the last five years) still has the demographic behavior of the region of origin (considering migration, fertility and mortality trends). After a longer period of time, she would absorb the levels and trends of the demographic characteristics of the region of destination. Thus, when children who migrated from region $i$ to $j$ are multiplied by two, there is the assumption that the demographic patterns that the woman is currently experiencing are the same as the ones of the region of origin, because this is a recent migration. 
The ideal correction for the indirect effect of migration would be to know how many children between zero and four years of age were born after the migration of their parents. This exercise would require that the information of emigrant mothers should be allocated to their children below five years of age, using variables that identify household of residence. The children born in the region of destination, and whose mothers are migrants would be included in the numerator and denominator of the emigration rate from the regions considered. This is a complex estimation that could be even more complicated if one considers that some children in the household might not live with their mothers. Thus, the multiplication by two is an approximation for the estimation of migration for children between zero and four years of age.

An example which can calculate the weights of a child in Equation (2) is for one infant with three years of age who lives two years in the place of usual residence. This child will have two and a half person-years exposed to the risk of migrating in the current residence $\left(2.5 K_{2, . j}^{0}-\right.$ destination). The difference between child's age (three years) and the number of years in the final residence (two years) equals the amount of time that this child was exposed to the risk of migration from the place of previous residence $\left(1.0 K_{2, i .}^{0}-\right.$ origin). The sum of these two weights (2.5 and 1.0) equals the child's age (three years) added by one half to correct for the Census date of reference. In this example, the weight for the previous place of residence has to be multiplied by two $\left(2 * 1.0 K_{2, i}^{0}\right.$ ), as well as the numerator $\left(2 * K_{2, i j}^{0}\right)$, because of indirect migration. The sum of weights for migrant children equals the single weight for non-migrant children with the same age.

New equations to estimate migration level are now exhibited and explained. The level of migration is calculated by an estimator called total emigration rate. However, the total non-emigration rate $\left(T N E R_{i j}\right)$ is first estimated. Since the $A S E R_{x, i j}$ are not probabilities, but "forces of migration" ("hazards of migration," or average continuous rates), some discussion about forces of mortality is developed in order to clarify the new migration equations proposed in the sequence.

Concerned about force of mortality in the life table framework, Hinde (1998) explains that "the division of people's lives into years of age is purely for analytical convenience. It implies that the risk of death changes abruptly each birthday. This, of course, is not true for most people. Mortality is really continuously changing with age." (Hinde 1998: 35) The force of mortality is the same as the hazard function, and is an instantaneous measure of dying at any exact age $x$. This is not a probability, because this force can take a value greater than one unit. 
As in the present article, the risk of migration does not change suddenly in each age group. Migration is a continuous process varying with age. Moreover, the $A S E R_{x, i j}$ can also take a value greater than one unit, taking into account that people at the risk of migrating can move more than once in a specific time interval.

Furthermore, Hinde explains that "the hazard function is simply the instantaneous rate of change of this conditional probability of death. It is denoted by the symbol $h(x)$. In other words, the hazard function at age $x$ is a measure of the intensity of the mortality in the very small interval $\mathrm{d} x$ between exact ages $x$ and $x+\mathrm{d} x$." (Hinde 1998: 65-66)

The following equations were extracted from Hinde (1998: 66-67). The hazard function $[h(x)]$ is related to the survivor function $\left[S(x)=l_{x} / 1_{0}\right]$ by:

$$
h(x)=\lim _{d x \Rightarrow 0}\left[\frac{S(x)-S(x+d x)}{S(x) d x}\right]=-\lim _{d x \Rightarrow 0}\left[\frac{S(x+d x)-S(x)}{S(x) d x}\right]=-\frac{1}{S(x)} \lim _{d x \Rightarrow 0}\left[\frac{S(x+d x)-S(x)}{d x}\right]=-\frac{1}{S(x)} \frac{d}{d x} S(x) .
$$

The equation above generates the following ones:

$$
h(x)=-\frac{d}{d x}[\ln S(x)] \Rightarrow \ln S(x)=-\int_{0}^{x} h(u) d u \Rightarrow S(x)=\exp \left[-\int_{0}^{x} h(u) d u\right] .
$$

The force of mortality is illustrated by Preston, Heuveline and Guillot (2004: 60) as $\mu(x)$ :

$$
\mu(x)=\lim _{n \rightarrow 0}\left[\frac{l(x)-l(x+n)}{n \cdot l(x)}\right]
$$

Applying the definition of a derivative,

$$
\mu(x)=\frac{-d \ln (l(x))}{d x} \Rightarrow-\int_{y}^{z} \mu(x) d x=\ln l(z)-\ln l(y) \Rightarrow e^{-\int_{y}^{z} \mu(x) d x}=\frac{l(z)}{l(y)}
$$

The equation above "is one of the most important equations in formal demography. It expresses the proportionate change in the size of a cohort between two ages completely in terms of the force of mortality function prevailing between those ages. It says that the proportionate change in cohort size between $y$ and $z$ is a simple function of the sum of the force of mortality function between those ages. The order in which the death rates occur is immaterial; all that matters is their sum." (Preston, Heuveline and Guillot 2004: 60) 
In the case of the estimations of this study, the age-specific emigration rate (force of migration) has a relationship with the total non-emigration rate (non-emigration function), which is analogous to the relationship between the force of mortality and the survivor function. Thus the equation below illustrates how the total non-emigration rate is estimated:

$T N E R_{i j}=\exp \left[-\int_{0}^{x} A S E R(u) d u\right]=\exp \left(-\sum A S E R_{x, i j}\right)$.

Finally, the total emigration rate $\left(T E R_{i j}\right)$ is calculated. This rate is the difference between one unit and the total non-emigration rate. The following equation demonstrates the form to estimate the total emigration rate:

$T E R_{i j}=1 \quad T N E R_{i j}$.

The 1991 and 2000 Brazilian Censuses also have information on place of residence five years prior to the enumeration that can be used to estimate migration rates. In the numerator, the amount of people who lived in another place five years before the Census is estimated. In the denominator, the total number of individuals exposed to the risk of migration is computed. The denominator of this equation is multiplied by five. This procedure is applied to furnish an annual average rate. When using the place of residence five years before the Census, migration rates for people between zero and five years of age are not able to be estimated.

An assumption is made to calculate migration rates using this procedure. The rate of emigration is the same between those who died during the five years before Census and those who survived during this same period.

The equation below illustrates how to calculate age-specific emigration rates using data on place of residence at a fixed time prior to the Census:

$$
A S E R_{x, i j}=\frac{\sum K_{i j}^{x}}{t * \sum\left[\frac{\left(K_{i .}^{x}+K_{i i}^{x}\right)+\left(K_{i}^{x}\right)}{2}\right]},
$$


in which $A S E R_{x, i j}$ is the age-specific emigration rate from region $i$ to region $j$ for age group $x ; K_{i j}^{x}$ refers to migrants that lived in region $i$ at the beginning of the period and moved to region $j$ at the end of the period for age group $x ; K_{i}^{x}$. refers to migrants that lived in region $i$ at the beginning of the period, and live in another region at the end of the period for age group $x ; K_{i i}^{x}$ is the population that lived in region $i$ at the beginning, as well as at the end of the period for age group $x ; K_{i .}^{x}+K_{i i}^{x}$ is the total population at the beginning of the period for age group $x ; K_{i}^{x}$ is all the population that lived in region $i$ at the end of the period (this is the total population at the end of the period) for age group $x ;\left[\left(K_{i .}^{x}+K_{i i}^{x}\right)+\left(K_{i}^{x}\right)\right] / 2$ is the estimated population at the middle of the period for age group $x ; t$ is the number of years between the date of reference of the Census and the fixed prior time available in the migration question (1991 and 2000 Brazilian Censuses ask where people lived exactly five years before the Census, $t=5$ ).

\section{Data}

The 1970, 1980, 1991 and 2000 Brazilian Censuses microdata were utilized in this study to estimate migration rates. Caetano (2003) summarizes all migration variables that are available in the 1960-2000 Brazilian Censuses. He provides a chart including all questions on population flows, attempting to make the variables comparable across the years when they are available in more than one Census. The chart can be summarized as: (1) state or country of birth was obtained in all Censuses; (2) nationality is also available in all Censuses; (3) 1991 and 2000 Censuses provide the year in which foreigners moved to Brazil; (4) 19702000 Censuses have information on whether the person was born in the municipality of residence; (5) in the 2000 Census, there is information on whether the person has lived in the municipality of residence since birth; (6) 1980 and 1991 Censuses identify if respondent lived in rural and/or urban areas in the municipality of residence; (7) in 1991, if the person lived in both rural and urban areas in the municipality, he/she also relays the amount of years of the last movement; (8) all Censuses have information on number of years that the respondent lives in the municipality; (9) 1960-2000 Censuses have information on state or country of previous residence; (10) only 1980 and 1991 Censuses also have information on the municipality of previous residence if the person lived less than ten years in the municipality; (11) the 2000 Census indicates whether the respondent was born in the state of residence; (12) information on the amount of years of continuous residence in the state is available for 1970-2000 Censuses; (13) all Censuses asked respondent whether he/she lived in rural or urban area in the municipality of previous residence; (14) in the 2000 Census, there is information on whether the person lived in this/other municipality, as well as in urban/rural area in July 31, 1995 (five years before the Census); (15) 1991 and 2000 Censuses asked in which municipality and state (or country) the person lived exactly five years before the Census; (16) in 1991 Census, there is specification 
of the type of area (urban or rural) of the residence five years before the Census (in September 1, 1986); (17) finally, the 2000 Census has information on which municipality and state (or country) the person works or studies.

Age-specific emigration rates $\left(A S E R_{x, i j}\right)$ were first estimated using information of state of previous residence (last-move data) and amount of years of continuous residence in the state (duration of residence). As explained above, all Censuses also provide the number of years of residence in the municipality, and for 1980 and 1991 they also offer the municipality of previous residence. However, since the main purpose of this study is to improve techniques developed by Machado (1993), only state-level variables were needed to get rates among the five Brazilian major-regions (North, Northeast, Southeast, South, and Center-West), as used in that study. Then, 160 migration curves were generated ( 2 sexes $* 4$ years $* 5$ regions of origin $*$ 4 regions of destination), using the statistical software SAS, and were organized on 40 graphs ( 2 sexes * 5 regions of origin $* 4$ regions of destination) which have four curves each, illustrating each Census year. These graphs were arranged on a set of 10 figures.

Another set of estimations were calculated using information on place of residence at a fixed prior time for the 1991 and 2000 Censuses. This type of estimation is possible because these Censuses provide information of municipality and state (or country) in which the person lived exactly five years before the Census. Rates calculated using this technique were compared to the first set of rates, in order to test the accuracy of Machado's technique. A total of 80 migration curves were generated $(2$ sexes $* 2$ years $* 5$ regions of origin $* 4$ regions of destination). These curves are compared to the ones estimated with information of last-move data, and were organized on 80 graphs ( 2 sexes $* 2$ years $* 5$ regions of origin $* 4$ regions of destination) which have two curves each, illustrating the two types of estimation. These graphs were set up on a group of 20 figures.

Some of these figures were selected in order to show levels of age-specific emigration rates $\left(A S E R_{x, i j}\right)$. As mentioned above, these graphs enable the comparison between rates calculated with last-move data and duration of residence to the ones generated with place of residence at a fixed date in the past. Proportional age-specific emigration rates were also estimated, in order to analyze patterns of migration rates. Estimation of these proportional rates is possible by making the sum across the five-year age groups be equal to one unit. Total emigration rates $\left(T E R_{i j}\right)$ by major-region and sex were also estimated in this study.

Censuses data were also utilized to estimate the total number of emigrants, as well as the proportion of these emigrants in the population of origin by major-region and sex for all four periods. The calculation of these 
migrant stocks provided the description of these movements in absolute numbers, assessing the richness of estimates offered by information on place of previous residence (last-move data) and duration of residence.

Migration rates between the Northeastern and Southeastern regions were selected to be evaluated in this research. Internal migration flows in Brazil have the highest levels from Northeastern to Southeastern states. A combination of the poverty and lack of job opportunities in the Northeast, and the concentration of industries in the Southeast, mainly in the state of São Paulo, is the usual explanation for this population movement. Another interesting factor on these migration streams is the returning migration. Censuses data have been indicating that rates from Southeast to Northeast have been increasing over the last decades. Because of these dynamic socioeconomic characteristics, these unique migration rates were selected for analysis.

A specific data treatment must be utilized in the 1970 and 1980 Censuses for the states of Goiás and Tocantins in order to estimate their migration rates. These states formed a single area until 1988, when the new Brazilian constitution established the separation of Goiás, and the creation of Tocantins on the northern portion of this area. Goiás continued to be on the Center-Western region, but Tocantins became part of the Northern region. Since the 1980 Census also provide the municipality of previous residence, as well as municipality of current residence, it is possible to estimate migration rates even at the municipality level for the 1975-1979 period. The 1970 Census provides municipality of current residence, and only state of previous residence (not municipality). Then, migration rates for the 1965-1969 are not accurate when measuring flows that originated in the Center-Western and Northern regions. More specifically, for the 1965-1969 data, migration rates from the Center-Western region are overestimated, because of the inclusion of population streams from Tocantins. At the same time, rates from the Northern region are underestimated, because of the exclusion of migrants from Tocantins who are included in the Center-Western rates. However, this is not an issue for this present study, because only rates between the Northeastern and Southeastern regions are being analyzed.

\section{Results}

Techniques discussed in the previous sections were applied to the population flows between the Brazilian Northeastern and Southeastern major-regions. During the 1960s and 1970s, the migration from the Northeast to the Southeast was characterized by a rural to urban migration. Lower class people migrated and still migrate to the Southeast, mostly to São Paulo, since this state is Brazil's most industrial and has numerous job opportunities. Currently, the most important flow is the urban-urban migration. Two aspects of this new pattern are the increasing significance of middle size cities and the intra-metropolitan migration. 
The intra-metropolitan migration occurs between central urban areas to peripheral territories. On one hand, upper classes are segregated in gated communities isolated from lower classes. On the other hand, lowincome people are concentrated in deteriorated urban areas. Internal migration became more complex, with a wide variety of places of origin and destination and a change in the socioeconomic characteristics of migrants (Roberts 1995; Cerrutti and Bertoncello 2003; Baeninger 2000).

The rates estimated in this paper cannot verify the hypothesis of whether migration from rural to urban areas has been substituted by urban to urban migration. The intention instead is to analyze the levels and patterns of migration flows between the Brazilian Northeastern and Southeastern regions. In order to accomplish this, some data will be presented, such as the number of migrants moving between the two selected majorregions, the proportion of migrants in the population of origin, the total emigration rate $\left(T E R_{i j}\right)$, and the curves of estimated and proportional age-specific emigration rates $\left(A S E R_{x, i j}\right)$.

Table 1 illustrates that the number of migrants moving from the Northeast to the Southeast increased from 1965-1969 to 1995-1999. For instance, female migration increased almost two and a half times (from $257,916$ to 632,166$)$ from the first to the last period. Migration flows from the Southeast to the Northeast improved significantly. The male migration expanded more than ten times $(33,413$ to 354,671$)$ from $1965-$ 1969 to 1995-1999. A better way to analyze the level of migration flows is through the proportion of migrants of the population of origin, and the total emigration rates. These estimates are a more accurate measure for understanding the magnitude of population streams, instead of gross numbers, because the size of population that had the risk to migrate is taking into account. 
Table 1: Emigration Descriptive Statistics by Sex for the Northeast and Southeast, 1965-1969, 19751979, 1986-1990, 1995-1999

\begin{tabular}{|c|c|c|c|c|c|c|c|c|}
\hline \multirow{2}{*}{ Region } & \multicolumn{2}{|c|}{ 1965-1969 } & \multicolumn{2}{|c|}{ 1975-1979 } & \multicolumn{2}{|c|}{ 1986-1990 } & \multicolumn{2}{|c|}{ 1995-1999 } \\
\hline & Male & Female & Male & Female & Male & Female & Male & Female \\
\hline \multicolumn{9}{|c|}{ Total Number of Emigrants } \\
\hline Northeast to Southeast & 275,271 & 257,916 & 479,296 & 475,917 & 466,599 & 462,223 & 584,140 & 632,166 \\
\hline Southeast to Northeast & 33,413 & 31,537 & 131,967 & 122,312 & 220,213 & 199,642 & 354,671 & 319,506 \\
\hline \multicolumn{9}{|c|}{ Population at the Beginning of the Period } \\
\hline Northeast to Southeast & $15,231,876$ & $15,647,004$ & $17,922,897$ & $18,661,136$ & $21,386,107$ & $22,347,267$ & $24,125,153$ & $25,153,124$ \\
\hline Southeast to Northeast & $19,356,335$ & $19,433,996$ & $24,854,997$ & $25,082,990$ & $30,494,899$ & $31,387,211$ & $34,533,615$ & $35,955,314$ \\
\hline \multicolumn{9}{|c|}{ Proportion of Emigrants on the Population of Origin } \\
\hline Northeast to Southeast & 0.0181 & 0.0165 & 0.0267 & 0.0255 & 0.0218 & 0.0207 & 0.0242 & 0.0251 \\
\hline Southeast to Northeast & 0.0017 & 0.0016 & 0.0053 & 0.0049 & 0.0072 & 0.0064 & 0.0103 & 0.0089 \\
\hline \multicolumn{9}{|c|}{ Total Emigration Rate $\left(T E R_{i j}\right)$} \\
\hline Northeast to Southeast & 0.0635 & 0.0591 & 0.0808 & 0.0780 & 0.0642 & 0.0611 & 0.0737 & 0.0768 \\
\hline Southeast to Northeast & 0.0057 & 0.0051 & 0.0179 & 0.0165 & 0.0235 & 0.0212 & 0.0353 & 0.0310 \\
\hline
\end{tabular}

Source: IBGE 1970, 1980, 1991, 2000.

Total emigration rates $\left(T E R_{i j}\right)$ illustrate that migration flows from the Northeast to the Southeast experienced an increase from 1965-1969 to 1975-1979, a decrease from 1975-1979 to 1986-1990, and an increase from 1986-1990 to 1995-1999 (Table 1). An explanation for this trend could be related to different levels of economic growth experienced in Brazil over time. Figure 1 shows data from 1948 to 2006 for both the Brazilian gross domestic product (GDP) - in millions of Brazilian Reais, using 2006 as the baseline year to calculate real income - as well as the percent GDP real annual variation (IPEA 2008; IBGE and SCN 2007). As illustrated in Figure 1, the 1970s economy had a sharp increase in GDP levels, as well as high levels of GDP real annual variation. Since economic development was more concentrated in the Southeastern region, with the implementation of industries and services, this might be an explanation for the high levels of migration from the Northeast to the Southeast in 1975-1979. In the 1980s, the Brazilian economy experienced a significant stagnation compared to the previous period. GDP real annual variation presented negative values in several years, resulting in a decrease of GDP levels in the first years of this decade. This could be a cause of the decline in migration from the Northeast to the Southeast in 1986-1990 compared to 1975-1979. In more recent years, the economy shows better growth indices, which could have influenced the increase of emigration rates from the Northeast to the Southeast in 1995-1999 compared to the previous period. 
Figure 1: Brazilian Gross Domestic Product (GDP) in Millions of Brazilian Reais (values using 2006 as the baseline), and Percent GDP Real Annual Variation, 1948-2006

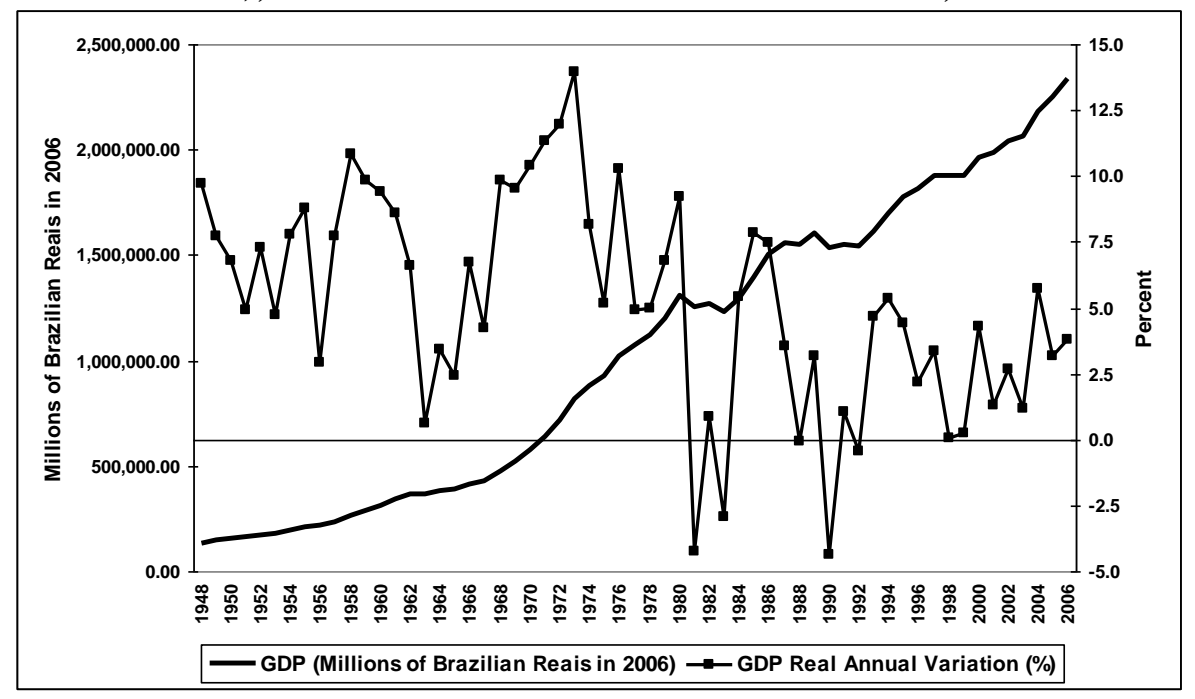

Source: IPEA 2008; IBGE and SCN 2007.

In relation to the flows from the Southeast to the Northeast, total emigration rates increased significantly over the decades. From 1965-1969 to 1995-1999, both male and female $T E R_{i j}$ s increased more than six times (from 0.0057 to 0.0353 , and from 0.0051 to 0.0310 , respectively). This might be an indication of migrants' returning to their region of origin after living in the Southeastern region. This analysis is in correlation with findings that São Paulo still plays a central role in the attraction of migrants from the Northeastern region, at the same moment that important returning flows have been increasing from the Southeast to the Northeast (Baeninger 2000).

Table 1 also shows that $T E R_{i j}$ s are higher for women than for men in the last period of the NortheastSoutheast flow. This result is in opposition to the assessment made by Rogers and Castro (1981), in which the selectivity of migration would present higher rates for men than for women. This data might be suggesting that areas with more opportunities for insertion in the labor market, characterized by more modern industries (Southeast), tend to attract women from less developed areas (Northeast). On the other hand, migration rates from the Southeast to Northeast present higher levels for men than for women, in all periods. In this case, areas with fewer opportunities for women to enter in the labor force attract more male migrants.

Figure 2 provides an alternative way to analyze the level of migrants between the Northeastern and Southeastern regions. These rates are reported in Tables 1 and 2 of Appendix 1. First, age-specific emigration rates $\left(A S E R_{x, i j}\right)$ indicate that migration from Northeast to Southeast is much greater than from Southeast to Northeast for both sexes during all periods. Migration flows from the Northeastern to the 
Southeastern region had higher levels in 1975-1979, compared to the other periods. These rates are greater for young adults (15-30 years of age), who are a component of the economically active population. Thus Figure 2 emphasizes the previous discussion involving the relationship between higher economic growth experienced in Brazil during the 1970s and greater levels of migration rates from the Northeast to the Southeast. Rates for women between 1995-1999 suggest that they experienced a greater increase in migration flows than men, which is in line with higher $T E R_{i j}$ s for females than for males in this last period, presented in Table 1.

Figure 2: Age-specific Emigration Rates $\left(A S E R_{x, i j}\right)$ by Age Group and Sex for the Northeast and Southeast, 1965-1969, 1975-1979, 1986-1990, 1995-1999
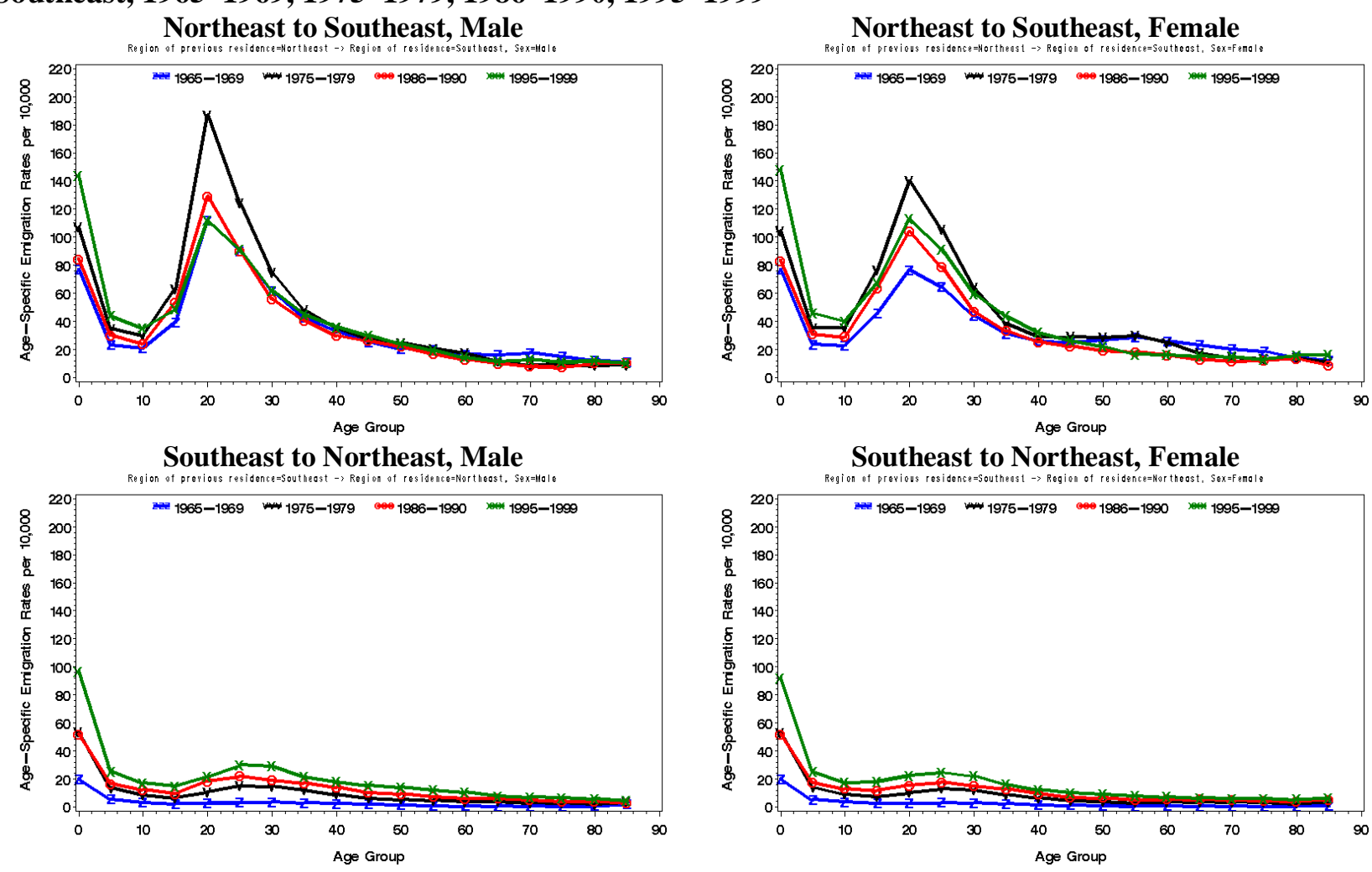

Source: IBGE 1970, 1980, 1991, 2000

$A S E R_{x, i j}$ s from the Southeastern to the Northeastern region illustrate a gradual increase in migration levels over time for both men and women (Figure 2). These migration levels might suggest that returning migration is experiencing higher levels in recent decades than in the previous ones. An analysis of the composition of migrants from Southeast to Northeast by state of birth would provide more appropriate information on whether these flows occurred as a result of Northeasters returning to their region of birth, after a period of migration to the Southeast. This analysis was not conducted in the present study, because this would create a whole new set of analysis, which is not the goal of this research. 
A deeper understanding of the patterns of migration rates can be addressed by the analysis of the following proportional age-specific emigration rates. Figure 3 illustrates proportional $A S E R_{x, i j}$ s between the Northeast and Southeast. These rates provide information for understanding migration patterns. The estimation of proportional rates was generated using the $A S E R_{x, i j}$ in Figure 2, making the sum of rates across age groups equal to one unit. These curves show that migration from the Northeastern to the Southeastern region is concentrated between age groups 15-19 and 30-34. This is a typical migration flow of people moving for job opportunities, in which rates are higher for individuals of labor age. In the case of migration from the Southeast to the Northeast, the importance of rates within earlier ages is much higher. This is consistent with the assessment that this migration is more related to familial movements. Thus, the migration movements between those areas have different patterns. The data is reinforcing the consideration that the Southeastern region has more job opportunities for persons of labor age, and the Northeastern region is more attractive to a familial migration pattern.

Figure 3: Proportional Age-specific Emigration Rates $\left(A S E R_{x, i j}\right)$ by Age Group and Sex for the Northeast and Southeast, 1965-1969, 1975-1979, 1986-1990, 1995-1999
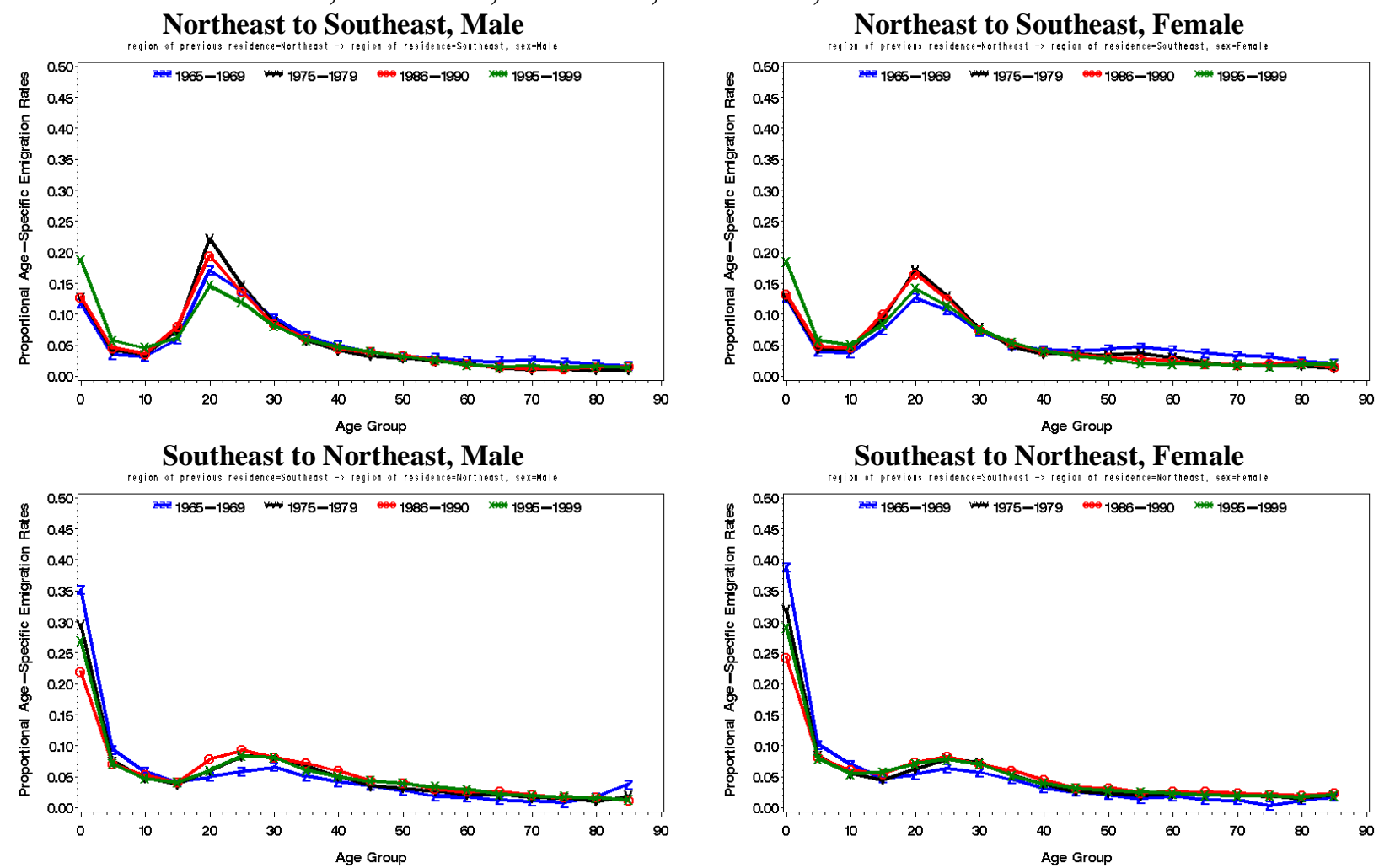

Source: IBGE 1970, 1980, 1991, 2000.

The finding that the Southeast-Northeast curves have higher rates for children than in the NortheastSoutheast flows poses the need for further discussion. This result is in agreement with a study developed by Jannuzzi (2000), in which he used a 1993 regional household survey for the state of São Paulo to generate 
a series of migration rates by age. In this survey the respondents were asked the reason for their migration movement, which might be related to work, family, life cost, quality of life, marriage, school services, or retirement. Moreover, migrants also indicated whether they moved alone, with the household head, with their nuclear family, or with other relatives who were a part of their extended family. Exploring this variety of information, Jannuzzi argues that migration is no longer solely explained by labor determinants. Thus the patterns of migration rates by age are not always similar to the model proposed by Rogers and Castro (1981). For instance, migration flows caused by returning migration present greater values for the younger age groups compared to other age groups. This finding is due to the fact that returning migration occurs by the whole family moving from one region to another. As a consequence, the rates for children are greater than the ones for the other age groups.

Schmertmann (1999) utilized information on last-move data and duration of residence to estimate migration rates with the 1980 Brazilian Census. In a specific case, he estimated that there was a greater migration in 1975-1980 from Paraná to Brazilian locations other than São Paulo, compared to the full decade (19701980). Furthermore, the migration pattern between Paraná and these destinations have greater rates for the younger age group (10-14), and declining rates from the 20-24 age group to the following ones. He omits individuals younger than ten years of age, because they were not exposed to the risk of migration for the entire period. However, in the present study the inclusion of the youngest groups is followed by a correction that takes into account indirect migration, such as the pattern explained above.

This example provided by Schmertmann can be interpreted as analogous to this article's estimates from the Southeast to Northeast, both because of the sharp increase in the rates experienced in more recent periods, and because of the similar patterns by age originated by the migration rates. Thus the different migration patterns estimated by Jannuzzi and Schmertmann are evidence that rates do not follow only the labor migration schedule elaborated by Rogers and Castro. Patterns of migration by age depend on the regions and time being considered in the analysis, as well as on the reasons for migration.

Furthermore, a reason for the higher rates of migration for children between zero and four years of age in the Southeast-Northeast curves might have substantive explanations. Previous studies characterize these flows as returning migration (Jannuzzi 2000; Baeninger 2000), in which families are moving back to the Northeast after a previous migration to the Southeast. Thus mothers had already given birth to all their children before returning to the Northeast, and are now moving with the whole family. In other words, these women do not tend to have more children after their return to Northeast. When the correction for indirect migration is done, following the strategies explained above, there is an overestimation of the number of 
children who migrated from the Southeast to the Northeast. If this is true, the problem is that the migration formula could not be changed for one specific flow (Southeast-Northeast) and not for the other one (Northeast-Southeast). In any case, this is an empirical issue that does not reduce the robustness of the formula and estimations presented above, since the general level and patterns of migration are well calculated, and are in agreement with previous studies concerned about internal migration in Brazil (Schmertmann 1999; Jannuzzi 2000).

\section{Discussion}

The empirical results presented above emphasize that the technique developed by Machado (1993) is very important for migration studies. Migration levels can be examined by total emigration rates $\left(T E R_{i j}\right)$ and agespecific emigration rates $\left(A S E R_{x, i j}\right)$, and migration patterns are evaluated through the shape of proportional age-specific emigration rates. The procedure proposed by Machado is a technique to estimate migration rates that address questions of place of previous residence (last-move data), as well as duration of continuous residence in a specific area. In Brazil, this information is provided by the 1970, 1980, 1991 and 2000 Censuses. The other technique to estimate migration rates utilizes questions about residence five years before the Census. This information was first gathered in Brazil as part of the 1991 Census, and repeated in the 2000 Census.

It is important to note that some alterations were made to Machado's technique, because his equation presented a possibility for errors. In the denominator of the equation, some changes were applied, and some terms were added. It is essential to include the component of emigration in the denominator. Moreover, weights need to be changed to produce more accurate migration rates. In the numerator, a specific change must be conducted. Children between zero and five years of age must have special multipliers (weights). This correction allows for the indirect effect of migration. This procedure prevents the underestimation of migration rates within these early ages. These corrections to Machado's technique are an improvement in the study of migration.

Figure $4^{3}$ illustrates previous estimates done by Machado (based on Equation 1) and new estimates proposed in this study (Equation 2). Machado estimated rates only up to the group of people with at least 75 years of age, and are reported in Table 1 of Appendix 2. However, it is still possible to conduct a comparison. First of all, rates for the first age group were underestimated by Machado's study for all migration streams. Furthermore, rates for the remaining age groups were overestimated by Equation (1), due to the lack of terms now added in the denominator of Equation (2). New estimates are much closer to previous theories and studies concerned with labor migration, in which young adults (20-24) present the highest rates, 
teenagers (10-19) have the lowest, and children (0-9) reflect rates of their parents (26-40) (Rogers and Castro 1981).

Figure 4: Age-specific Emigration Rates $\left(A S E R_{x, i j}\right)$ by Age Group and Sex for the Northeast and Southeast, Using Rates Estimated by Machado (Equation 1) and Corrected Rates (Equation 2), 19751979
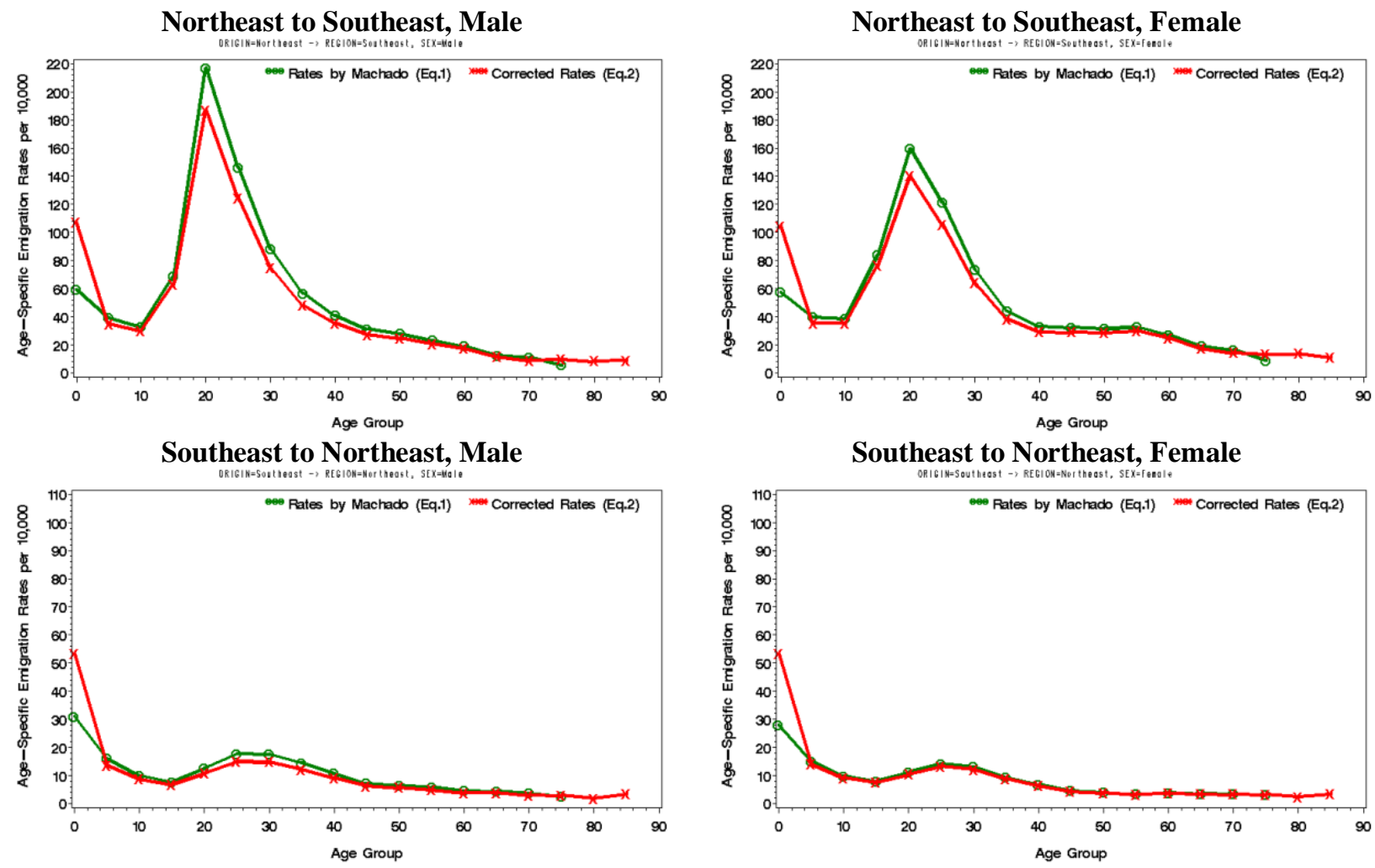

Source: Machado 1993; and IBGE 1980.

Migration rates estimated utilizing last-move data and duration of residence (Equation 2) are compared to those ones generated with place of residence at a fixed time prior to the enumeration (Equation 5). This comparison is presented in Figures 5 and 6, and provides a verification of the accuracy of the new estimates. Rates estimated with place of residence at a fixed time in the past are reported in Table 1 of Appendix 3. As is shown, migration rates using Machado's technique, with corrections from Equation (2), are extremely similar to the ones utilizing the other estimates (Equation 5) in 1986-1990 (Figure 5) and 1995-1999 (Figure 6). Similar trends are observed for both sexes, as well as for both migration streams (Northeast-Southeast, and Southeast-Northeast). Rates using Equation (2) are slightly higher than the ones estimated with Equation (5), mainly on Figure 6. However, the overestimation would have been even higher if the original Machado's technique had been used (Equation 1). 
Figures 5 and 6 also indicate that information on place of residence five years before the Census is unable to provide rates for the first age group (0-4). These children were not born five years before the Census, thus it is impossible to get this information. Following Rogers and Jordan's (2004) suggestion, rates for these children could be estimated using state or country of birth. However, the intention of this study is to generate and compare rates provided by estimations from each set of migration variables. Thus, information on last-move data and duration of residence has the advantage to estimate migration rates for more Brazilian Censuses than information on place at a fixed prior date, as well as to provide rates for all age groups.

Figure 5: Age-specific Emigration Rates $\left(A S E R_{x, i j}\right)$ by Age Group and Sex for the Northeast and Southeast, Using Data on Residence Five Years Before the Census (Equation 5) and Previous Residence (Equation 2), 1986-1990
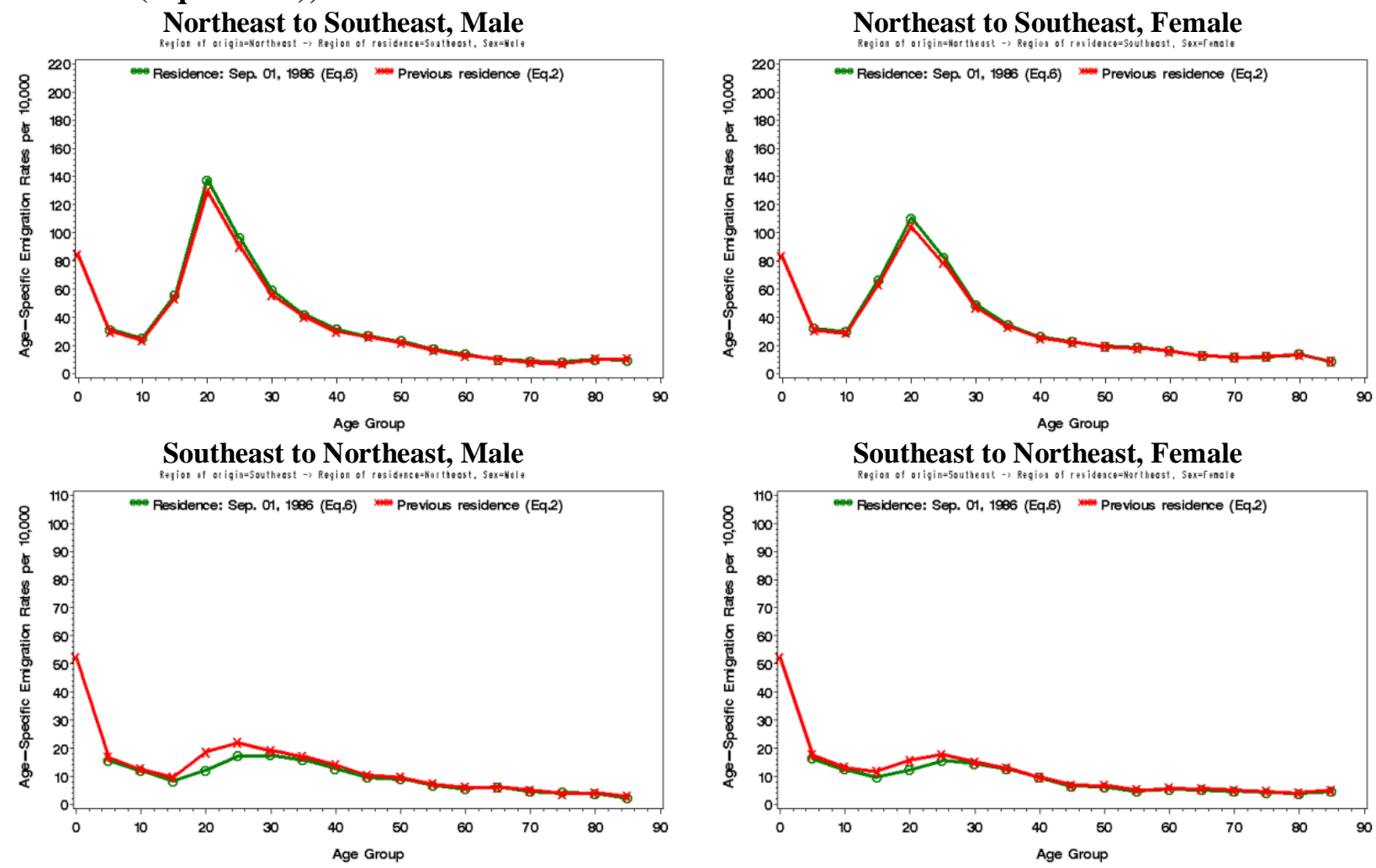

Source: IBGE 1991. 
Figure 6: Age-specific Emigration Rates $\left(A S E R_{x, i j}\right)$ by Age Group and Sex for the Northeast and Southeast, Using Data on Residence Five Years Before the Census (Equation 5) and Previous Residence (Equation 2), 1995-1999
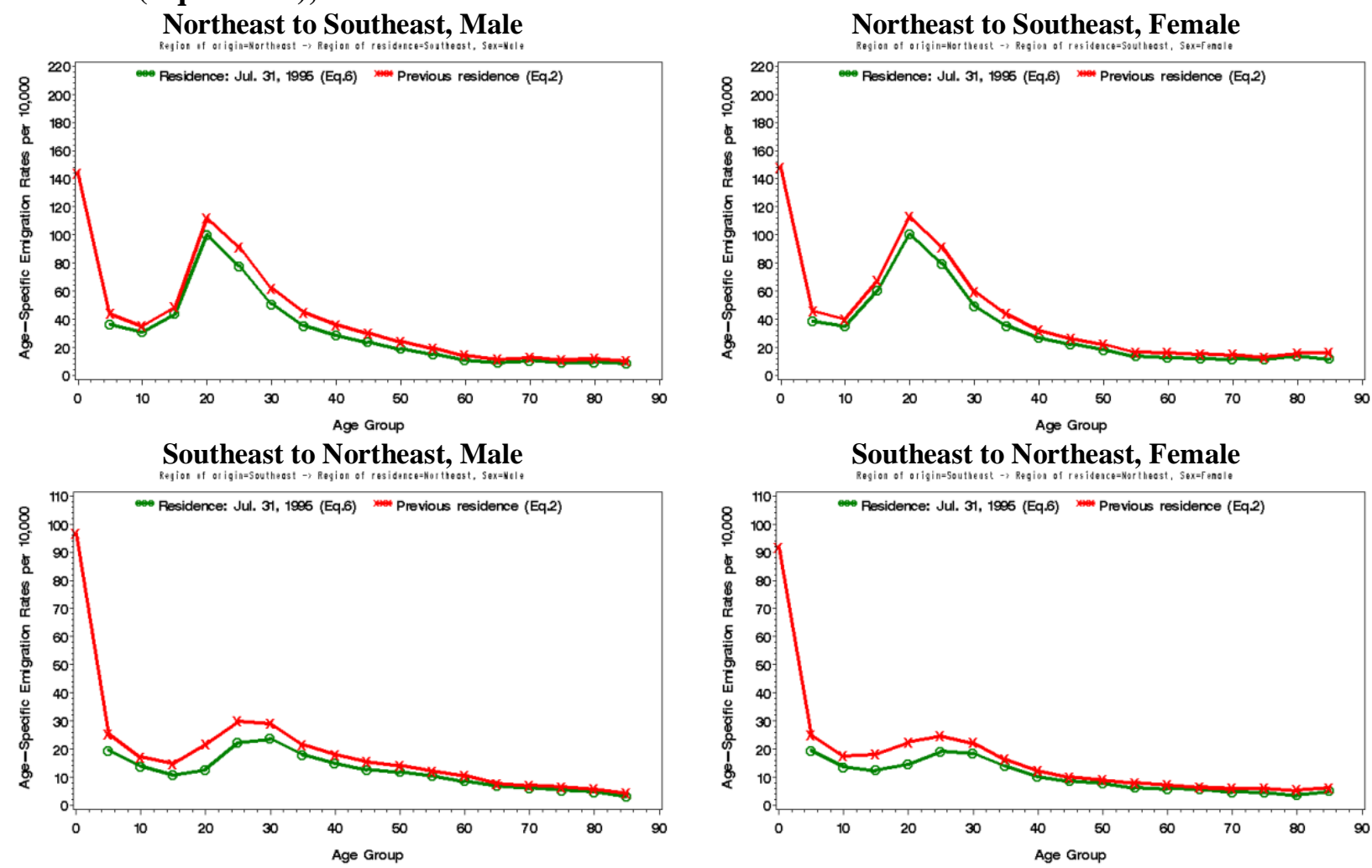

Source: IBGE 2000.

Some limitations are encountered in the 2000 Brazilian Census. Questions on place of previous residence (last-move data), as well as on duration of residence were collected only at the state (or country) level, but not at the municipality level. Therefore, it is not possible to estimate intra-state emigration rates with this kind of migration information. In the 2000 Census, intra-state analyses can be produced only using information of residence five years before the Census. Even with the difficulties of using the 2000 Brazilian Census, the improvements of Machado's technique described above is highly valuable.

In this paper I explained the techniques used to estimate migration transitions in discrete time and age, by comparing rates from last-move data and duration of residence, to those from place of residence at a fixed prior date. The clarification of previous limitations on migration estimations, as well as the elucidation of improvements needed to estimate accurate rates provide demographers with techniques that can be used for a worldwide range of Census data. Thus the equations exposed in this paper are a resource to verify how to estimate migration rates using different data (Bell 2005), enabling the study of levels and patterns of migration in several countries. Moreover, migration stocks were estimated using information on last-move data and duration of residence. The analysis of these absolute numbers is an important tool to better 
understand levels of migration between two areas. The multiple possibilities of migration measurement offered by information on last-move data and duration of residence (Xu-Doeve 2006) have been explored and developed by demographers throughout time. Additional developments in methodologies for estimating migration rates, as well as the creation of new techniques are possible through the use of real data and the application of such procedures into specific contexts (Rogers and Castro 1981; Schmertmann 1999; Jannuzzi 2000), and was the ultimate purpose of this paper. Further studies might improve the quality of techniques and results obtained by research in this area, enabling demographers to better understand migration levels and patterns. Such future improvements on migration studies would help generate additional scientific accomplishments, similar to the benefits gained by fertility and mortality research. 


\section{References}

Amaral, Ernesto F. L. (2002). Master's thesis: Funções de migração por idade e caracterização de migrantes das microrregiões de Goiás e Distrito Federal, 1975-1979 e 1986-1990. Belo Horizonte, Brazil: Center of Development and Regional Planning (CEDEPLAR), Federal University of Minas Gerais (UFMG).

Amaral, Ernesto F. L., Roberto N. Rodrigues and Moema G. B. Fígoli (2004). "Métodos e técnicas de mensuração de movimentos migratórios: Goiás e Distrito Federal, 1975-1979 e 1986-1990." Revista Brasileira de Estudos de População 21 (2): 283-301.

Baeninger, Rosana (2000). "São Paulo no Contexto dos Movimentos Migratórios Interestaduais," (pp.127169) in: Migração e Ambiente em São Paulo: Aspectos Relevantes da Dinâmica Recente, edited by D. J. Hogan, J. M. P. Cunha, R. Baeninger and R. L. Carmo. Campinas, Brazil: Population Studies Center (NEPO), University of Campinas (UNICAMP).

Bell, Martin (2005). "Towards Rigorous Cross-National Comparison of Internal Migration: Who Collects What?" Paper presented at the XXV International Population Conference of the International Union for the Scientific Study of Population (IUSSP), Tours, France, July 18 to 23, 2005.

Caetano, André J. (2003). IPUMS Technical Report - Migration Characteristics: Variáveis de Migração, Raça/Cor, Religião e Deficiências Mental e Físicas: Censos de 1960, 1970, 1980, 1991, 2000. Unpublished manuscript.

Cerrutti, Marcela and Rodolfo Bertoncello (2003). "Urbanization and Internal Migration Patterns in Latin America." Paper presented at the Conference on African Migration in Comparative Perspective, Johannesburg, South Africa, June 4 to 7, 2003.

Courgeau, Daniel, Vincent Nedellec and Pascal Empereur-Bissonnet (2000). "Duration of Residence in the Same Dwelling. A Test of Measurement using Electricity Utility Company Records.” Population: An English Selection 12: 335-342.

Hinde, Andrew (1998). Demographic Methods. London: Arnold.

IBGE (Brazilian Institute of Geography and Statistics) (1970). Census 1970: Microdata. Rio de Janeiro, Brazil: IBGE.

IBGE (Brazilian Institute of Geography and Statistics) (1980). Census 1980: Microdata. Rio de Janeiro, Brazil: IBGE.

IBGE (Brazilian Institute of Geography and Statistics) (1991). Census 1991: Microdata. Rio de Janeiro, Brazil: IBGE.

IBGE (Brazilian Institute of Geography and Statistics) (2000). Census 2000: Microdata. Rio de Janeiro, Brazil: IBGE.

IBGE (Brazilian Institute of Geography and Statistics) and SCN (Brazilian System of National Budgets) (2007). "Gross Domestic Product - GDP: Real Annual Variation." [http://www.ipeadata.gov.br, assessed March 2, 2008]

IPEA (Brazilian Institute of Applied Economics Research) (2008). "Gross Domestic Product - GDP." [http://www.ipeadata.gov.br, assessed March 2, 2008]

Jannuzzi, Paulo M. (2000). "Tasas específicas por motivos y acompañantes de la migración: una contribución a la interpretación y al uso de modelos de patrones etarios de migración." Notas de Población 28 (70): 33-85. 
Machado, Cláudio C. (1993). Ph.D. Dissertation: Projeções Multirregionais de População: o Caso Brasileiro (1980-2020). Belo Horizonte, Brazil: Center of Development and Regional Planning (CEDEPLAR), Federal University of Minas Gerais (UFMG).

Preston, Samuel H., Patrick Heuveline and Michel Guillot (2004). Demography: Measuring and Modeling Population Processes. Oxford: Blackwell Publishing.

Rees, Philip, Martin Bell, Oliver Duke-Williams and Marcus Blake (2000). "Problems and Solutions in the Measurement of Migration Intensities: Australia and Britain Compared." Population Studies 54: 207-222.

Roberts, Bryan (1995). The Making of Citizens. London: Edward Arnold.

Rogers, Andrei and Lisa Jordan (2004). "Estimating Migration Flows From Birthplace-Specific Population Stocks of Infants." Geographical Analysis 36 (1): 38-53.

Rogers, Andrei and Luis J. Castro (1981). Model Migration Schedules. Laxenburg, Austria: International Institute for Applied Systems Analysis.

Schmertmann, Carl P. (1999). "Estimating Multistate Transition Hazards From Last-Move Data." Journal of the American Statistical Association 94 (445): 53-63.

UNECE (2005). Report of the March 2005 Joint UNECE/EUROSTAT Seminar on Migration Statistics. CES/2005/39, Geneva: United Nations Economic Commission for Europe (UNECE), and Statistical Office of the European Communities (EUROSTAT).

Xu-Doeve, William L. J. (2006). "The Measurement of International and Internal Migration in the 2010 Global Round of Population Censuses: Twelve Key Recommendations on Questions, Concepts and Procedures." Paper presented at the European Population Conference of the European Association for Population Studies (EAPS), Liverpool, United Kingdom, June 21 to 24, 2006. 


\section{Appendix 1}

Table 1: Age-specific Emigration Rates $\left(A S E R_{x, i j}\right)$ by Age Group and Sex from Northeast to Southeast, Estimated with Information on Place of Previous Residence (Last-Move Data) and Duration of Residence (Equation 2), 1965-1969, 1975-1979, 1986-1990, 1995-1999

\begin{tabular}{|c|c|c|c|c|c|c|c|c|}
\hline \multirow{2}{*}{$\begin{array}{c}\text { Age } \\
\text { group }\end{array}$} & \multicolumn{4}{|c|}{ Male } & \multicolumn{4}{|c|}{ Female } \\
\hline & 1965-1969 & 1975-1979 & 1986-1990 & 1995-1999 & 1965-1969 & 1975-1979 & 1986-1990 & 1995-1999 \\
\hline $0-4$ & 0.007713 & 0.010679 & 0.008452 & 0.014370 & 0.007701 & 0.010449 & 0.008343 & 0.014788 \\
\hline $5-9$ & 0.002309 & 0.003478 & 0.003019 & 0.004388 & 0.002375 & 0.003533 & 0.003096 & 0.004587 \\
\hline $10-14$ & 0.002106 & 0.002991 & 0.002417 & 0.003534 & 0.002301 & 0.003543 & 0.002905 & 0.004033 \\
\hline 15-19 & 0.003950 & 0.006305 & 0.005330 & 0.004851 & 0.004573 & 0.007662 & 0.006361 & 0.006740 \\
\hline $20-24$ & 0.011213 & 0.018697 & 0.012913 & 0.011203 & 0.007690 & 0.014007 & 0.010422 & 0.011309 \\
\hline 25-29 & 0.009033 & 0.012445 & 0.009046 & 0.009142 & 0.006487 & 0.010558 & 0.007876 & 0.009130 \\
\hline 30-34 & 0.006189 & 0.007497 & 0.005602 & 0.006213 & 0.004397 & 0.006416 & 0.004715 & 0.005989 \\
\hline $35-39$ & 0.004299 & 0.004824 & 0.004070 & 0.004509 & 0.003126 & 0.003848 & 0.003346 & 0.004372 \\
\hline $40-44$ & 0.003306 & 0.003557 & 0.002994 & 0.003629 & 0.002626 & 0.002935 & 0.002542 & 0.003205 \\
\hline $45-49$ & 0.002547 & 0.002741 & 0.002606 & 0.003032 & 0.002493 & 0.002908 & 0.002232 & 0.002631 \\
\hline $50-54$ & 0.002067 & 0.002468 & 0.002214 & 0.002441 & 0.002699 & 0.002868 & 0.001912 & 0.002228 \\
\hline 55-59 & 0.001998 & 0.002069 & 0.001694 & 0.001964 & 0.002878 & 0.002999 & 0.001817 & 0.001678 \\
\hline $60-64$ & 0.001651 & 0.001739 & 0.001296 & 0.001429 & 0.002595 & 0.002486 & 0.001589 & 0.001626 \\
\hline $65-69$ & 0.001633 & 0.001158 & 0.001012 & 0.001137 & 0.002314 & 0.001741 & 0.001291 & 0.001560 \\
\hline $70-74$ & 0.001769 & 0.000898 & 0.000815 & 0.001301 & 0.002028 & 0.001424 & 0.001139 & 0.001498 \\
\hline $75-79$ & 0.001501 & 0.000984 & 0.000751 & 0.001110 & 0.001875 & 0.001343 & 0.001252 & 0.001299 \\
\hline 80-84 & 0.001257 & 0.000836 & 0.001027 & 0.001216 & 0.001454 & 0.001389 & 0.001345 & 0.001589 \\
\hline 85+ & 0.001103 & 0.000902 & 0.001052 & 0.001064 & 0.001253 & 0.001110 & 0.000899 & 0.001627 \\
\hline$T E R_{i j}{ }^{*}$ & $\mathbf{0 . 0 6 3 5 3 6}$ & 0.080816 & 0.064159 & 0.073679 & 0.059049 & $\mathbf{0 . 0 7 8 0 0 6}$ & 0.061136 & 0.076781 \\
\hline
\end{tabular}

Table 2: Age-specific Emigration Rates $\left(A S E R_{x, i j}\right)$ by Age Group and Sex from Southeast to Northeast, Estimated with Information on Place of Previous Residence (Last-Move Data) and Duration of Residence (Equation 2), 1965-1969, 1975-1979, 1986-1990, 1995-1999

\begin{tabular}{|c|c|c|c|c|c|c|c|c|}
\hline \multirow{2}{*}{$\begin{array}{c}\text { Age } \\
\text { group }\end{array}$} & \multicolumn{4}{|c|}{ Male } & \multicolumn{4}{|c|}{ Female } \\
\hline & 1965-1969 & 1975-1979 & 1986-1990 & 1995-1999 & 1965-1969 & 1975-1979 & 1986-1990 & 1995-1999 \\
\hline $0-4$ & 0.002004 & 0.005335 & 0.005208 & 0.009667 & 0.002004 & 0.005327 & 0.005193 & 0.009171 \\
\hline 5-9 & 0.000536 & 0.001368 & 0.001677 & 0.002539 & 0.000525 & 0.001402 & 0.001749 & 0.002494 \\
\hline 10-14 & 0.000332 & 0.000868 & 0.001254 & 0.001706 & 0.000360 & 0.000919 & 0.001314 & 0.001753 \\
\hline 15-19 & 0.000239 & 0.000675 & 0.000973 & 0.001477 & 0.000244 & 0.000751 & 0.001181 & 0.001823 \\
\hline $20-24$ & 0.000284 & 0.001079 & 0.001862 & 0.002176 & 0.000276 & 0.001042 & 0.001566 & 0.002244 \\
\hline $25-29$ & 0.000332 & 0.001499 & 0.002202 & 0.003001 & 0.000326 & 0.001324 & 0.001773 & 0.002465 \\
\hline $30-34$ & 0.000377 & 0.001487 & 0.001923 & 0.002918 & 0.000296 & 0.001214 & 0.001512 & 0.002223 \\
\hline 35-39 & 0.000292 & 0.001223 & 0.001710 & 0.002164 & 0.000236 & 0.000883 & 0.001297 & 0.001633 \\
\hline $40-44$ & 0.000239 & 0.000917 & 0.001407 & 0.001812 & 0.000163 & 0.000638 & 0.000972 & 0.001230 \\
\hline $45-49$ & 0.000203 & 0.000628 & 0.001027 & 0.001551 & 0.000133 & 0.000432 & 0.000689 & 0.000998 \\
\hline $50-54$ & 0.000159 & 0.000567 & 0.000950 & 0.001419 & 0.000106 & 0.000389 & 0.000687 & 0.000905 \\
\hline $55-59$ & 0.000106 & 0.000490 & 0.000723 & 0.001225 & 0.000076 & 0.000328 & 0.000519 & 0.000800 \\
\hline $60-64$ & 0.000101 & 0.000383 & 0.000608 & 0.001068 & 0.000096 & 0.000377 & 0.000564 & 0.000721 \\
\hline 65-69 & 0.000070 & 0.000389 & 0.000616 & 0.000781 & 0.000066 & 0.000348 & 0.000556 & 0.000643 \\
\hline $70-74$ & 0.000061 & 0.000294 & 0.000499 & 0.000706 & 0.000064 & 0.000347 & 0.000500 & 0.000603 \\
\hline $75-79$ & 0.000047 & 0.000293 & 0.000389 & 0.000651 & 0.000019 & 0.000323 & 0.000458 & 0.000606 \\
\hline $80-84$ & 0.000099 & 0.000186 & 0.000415 & 0.000583 & 0.000067 & 0.000248 & 0.000410 & 0.000545 \\
\hline $85+$ & 0.000214 & 0.000350 & 0.000281 & 0.000451 & 0.000094 & 0.000346 & 0.000507 & 0.000636 \\
\hline$T E R_{i j}{ }^{*}$ & 0.005681 & 0.017871 & $\mathbf{0 . 0 2 3 4 4 5}$ & $\mathbf{0 . 0 3 5 2 6 0}$ & 0.005140 & 0.016501 & 0.021220 & 0.031002 \\
\hline
\end{tabular}




\section{Appendix 2}

Table 1: Age-specific Emigration Rates $\left(A S E R_{x, i j}\right)$ by Age Group and Sex between Northeast and Southeast, Estimated by Machado (Equation 1), 1975-1979

\begin{tabular}{|c|c|c|c|c|}
\hline \multirow{2}{*}{$\begin{array}{c}\text { Age } \\
\text { group }\end{array}$} & \multicolumn{2}{|c|}{ Northeast-Southeast } & \multicolumn{2}{|c|}{ Southeast-Northeast } \\
\hline & Male & Female & Male & Female \\
\hline $0-4$ & 0.005920 & 0.005743 & 0.003097 & 0.002798 \\
\hline 5-9 & 0.003928 & 0.003976 & 0.001604 & 0.001509 \\
\hline $10-14$ & 0.003317 & 0.003903 & 0.000997 & 0.000975 \\
\hline $15-19$ & 0.006888 & 0.008424 & 0.000767 & 0.000797 \\
\hline $20-24$ & 0.021708 & 0.015960 & 0.001266 & 0.001117 \\
\hline 25-29 & 0.014639 & 0.012145 & 0.001777 & 0.001423 \\
\hline $30-34$ & 0.008851 & 0.007368 & 0.001764 & 0.001310 \\
\hline $35-39$ & 0.005698 & 0.004405 & 0.001447 & 0.000938 \\
\hline $40-44$ & 0.004089 & 0.003314 & 0.001080 & 0.000674 \\
\hline 45-49 & 0.003122 & 0.003249 & 0.000723 & 0.000454 \\
\hline $50-54$ & 0.002789 & 0.003174 & 0.000651 & 0.000406 \\
\hline $55-59$ & 0.002320 & 0.003285 & 0.000587 & 0.000344 \\
\hline $60-64$ & 0.001906 & 0.002711 & 0.000457 & 0.000392 \\
\hline $65-69$ & 0.001262 & 0.001911 & 0.000441 & 0.000356 \\
\hline $70-74$ & 0.001115 & 0.001663 & 0.000360 & 0.000347 \\
\hline $75+$ & 0.000548 & 0.000898 & 0.000257 & 0.000336 \\
\hline
\end{tabular}




\section{Appendix 3}

Table 1: Age-specific Emigration Rates $\left(A S E R_{x, i j}\right)$ by Age Group and Sex between Northeast and Southeast, Estimated with Information on Place of Residence at a Fixed Prior Date (Equation 5), 1986-1990, 1995-1999

\begin{tabular}{|c|c|c|c|c|c|c|c|c|}
\hline \multirow{3}{*}{$\begin{array}{l}\text { Age } \\
\text { group }\end{array}$} & \multicolumn{4}{|c|}{$1986-1990$} & \multicolumn{4}{|c|}{ 1995-1999 } \\
\hline & \multicolumn{2}{|c|}{ Northeast-Southeast } & \multicolumn{2}{|c|}{ Southeast-Northeast } & \multicolumn{2}{|c|}{ Northeast-Southeast } & \multicolumn{2}{|c|}{ Southeast-Northeast } \\
\hline & Male & Female & Male & Female & Male & Female & Male & Female \\
\hline 0-4 & & & & & & & & \\
\hline 5-9 & 0.003136 & 0.003217 & 0.001570 & 0.001634 & 0.003634 & 0.003858 & 0.001962 & 0.001949 \\
\hline 10-14 & 0.002539 & 0.003029 & 0.001206 & 0.001250 & 0.003119 & 0.003519 & 0.001388 & 0.001373 \\
\hline 15-19 & 0.005579 & 0.006688 & 0.000828 & 0.000971 & 0.004378 & 0.006038 & 0.001082 & 0.001248 \\
\hline 20-24 & 0.013775 & 0.011043 & 0.0012 & 0.001228 & 0.010023 & 0.010074 & 0.001277 & 0.001467 \\
\hline 25-29 & 0.009645 & 0.008278 & 0.0017 & 0.001563 & 0.007785 & 0.007955 & 0.002235 & 0.001916 \\
\hline $30-34$ & 0.005942 & 0.004899 & 0.001745 & 0.001447 & 0.005093 & 0.004950 & 0.002375 & 0.001853 \\
\hline $35-39$ & 0.004210 & 0.003469 & 0.001588 & 0.001267 & 0.003554 & 0.003546 & 0.001795 & 0.001392 \\
\hline $40-44$ & 0.003169 & 0.002607 & 0.001271 & 0.000952 & 0.002871 & 0.002686 & 0.001491 & 0.001024 \\
\hline 45-49 & 0.002678 & 0.002283 & 0.000961 & 0.000655 & 0.002394 & 0.002231 & 0.001281 & 0.000858 \\
\hline $50-54$ & 0.002318 & 0.001966 & 0.000913 & 0.000626 & 0.001906 & 0.001857 & 0.001190 & 0.000786 \\
\hline $55-59$ & 0.001755 & 0.001885 & 0.000691 & 0.000469 & 0.001523 & 0.001384 & 0.001053 & 0.000637 \\
\hline $60-64$ & 0.00140 & 0.001609 & 0.0005 & 33 & 0.001 & 0.001276 & 0.000 & 0.000599 \\
\hline 65-69 & 0.001003 & 0.001307 & 0.000634 & 0.000514 & 0.000926 & 0.001220 & 0.000692 & 0.000574 \\
\hline $70-74$ & 0.000894 & 0.001156 & 0.000465 & 0.000470 & 0.001069 & 0.001173 & 0.000619 & 0.000475 \\
\hline 75-79 & 0.000822 & 0.001214 & 0.000418 & 0.000412 & 0.000907 & 0.001144 & 0.000532 & 0.000459 \\
\hline 80-84 & 0.001008 & 0.001384 & 0.000394 & 0.000393 & 0.000946 & 0.001384 & 0.000485 & 0.000366 \\
\hline $85+$ & 0.000959 & 0.000889 & 0.000227 & 0.000462 & 0.000863 & 0.001201 & 0.000334 & 0.000513 \\
\hline
\end{tabular}

${ }^{1}$ The complete list of the 192 member states of the United Nations, including Montenegro admitted on June 28, 2006, is available online [http://www.un.org/News/Press/docs/2006/org1469.doc.htm, accessed June 22, 2008].

${ }^{2}$ Dr. José Alberto Magno de Carvalho, from the Center of Development and Regional Planning (CEDEPLAR) at the Federal University of Minas Gerais (UFMG), Brazil.

${ }^{3}$ On Figures 4, 5 and 6, y-axes for flows from Northeast to Southeast have the same scales as the ones on Figure 2. However, scales on graphs with flows from Southeast to Northeast were changed in order to better compare estimates from different equations. 